\title{
O Movimento dos Pequenos Agricultores na interface entre agricultura familiar e educação do campo
}

\author{
Ramofly Bicalho Santos ${ }^{1}$, David Richard ${ }^{2}$ \\ ${ }^{1}$ Universidade Federal Rural do Rio de Janeiro - UFRRJ. Departamento de Educação do Campo, Movimentos \\ Sociais e Diversidade. BR-465, Km 7, Seropédica, Rio de Janeiro - RJ. Brasil. ramofly@ gmail.com \\ ${ }^{2}$ Universidade Federal Rural do Rio de Janeiro - UFRRJ.
}

RESUMO: O artigo em questão é fruto das pesquisas desenvolvidas pelo Programa de Educação Tutorial - PET Educação do Campo e Movimentos Sociais na Universidade Federal Rural do Rio de Janeiro - UFRRJ. Ele aborda o protagonismo do Movimento dos Pequenos Agricultores - MPA, em relação à agricultura familiar e educação do campo. Nosso objetivo principal é conhecermos o plano camponês, uma das principais "armas" do MPA. Ele representa um contraponto à incapacidade estatal na criação de leis que apoiem os pequenos agricultores. Desenvolvemos uma pesquisa bibliográfica e documental, utilizando as seguintes fontes de investigação: legislações, portarias, decretos e referenciais sobre educação do campo no Brasil. Utilizamos ainda os dados do censo agropecuário de 2006, ressaltando o valor da agricultura familiar na mesa do brasileiro. Nesse contexto, verificamos que o processo de ensino e aprendizagem pode dialogar com a realidade concreta dos sujeitos, individuais e coletivos, articulados com a luta pela terra. Concluímos que a produção coletiva do saber em parceria com educandos(as), educadores(as), comunidades e os movimentos sociais de luta pela terra, pode dialogar com histórias, memórias, identidades, desejos, valores e reconhecimento, fortalecendo o debate em torno da educação do campo, na sua estreita relação com movimentos sociais, escolas do campo e universidades públicas.

Palavras-chave: Educação do Campo, Movimentos Sociais, Movimento dos Pequenos Agricultores, Agricultura familiar. 


\title{
The movement of small farmers in the interface between family farming and rural education
}

\begin{abstract}
The article in question is the result of research carried out by the Tutorial Education Program - PET Rural Education and Social Movements in UFRRJ - Rural Federal University of Rio de Janeiro. It addresses the role of the MPA Movement of Small Farmers, the interface between family farming and rural education. We work with the peasant plan, one of the main weapons of the MPA. It is a counterpoint to the state's incapacity to create laws to support small farmers. We developed a bibliographical and documentary research, using the following research sources: laws, ordinances, decrees and references on the field of education in Brazil. We also use the agricultural census data 2006, stressing the importance of family farming in the Brazilian table. In this context, we find that the process of teaching and learning must dialogue with the concrete reality of the subjects, individual and collective, linked to the struggle for land. We conclude that the collective production of knowledge in partnership with students / as, educators / as, communities and social movements struggling for land, can dialogue with stories, memories, identities, desires, values and recognition, strengthening the debate around education of the field for its close relationship with social movements, field schools and public universities.
\end{abstract}

Keywords: Rural Education, Social Movements, Movement of Small Farmers, Family Farming. 


\section{El movimiento de los pequeños agricultores en la interfaz entre la agricultura familiar y la educación rural}

RESUMEN. El artículo en cuestión es el resultado de la investigación llevada a cabo por el Programa de Tutoría Educación - Educación campo PET y los movimientos sociales en UFRRJ - Universidad Federal Rural de Río de Janeiro. Se examina la función del MPA - Movimiento de Agricultores Pequeños, la interfaz entre la agricultura familiar y la educación rural. Trabajamos con el plan de campesino, una de las principales armas de la AMP. Es un contrapunto a la incapacidad del Estado para crear leyes para apoyar a los pequeños agricultores. Hemos desarrollado una investigación bibliográfica y documental, utilizando las siguientes fuentes de investigación: las leyes, ordenanzas, decretos y referencias en el campo de la educación en Brasil. También utilizamos los datos del censo agrícola de 2006, haciendo hincapié en la importancia de la agricultura familiar en la tabla brasileña. En este contexto, nos encontramos con que el proceso de enseñanza y aprendizaje del diálogo mosto con la realidad concreta de los sujetos, individuales y colectivas, vinculada a la lucha por la tierra. Llegamos a la conclusión de que la producción colectiva de conocimiento en colaboración con los alumnos / as, educadores / as, las comunidades y los movimientos sociales que luchan por la tierra, puede dialogar con historias, memorias, identidades, deseos, valores y el reconocimiento, el fortalecimiento del debate en torno a la educación del campo por su estrecha relación con los movimientos sociales, escuelas de campo y las universidades públicas.

Palabras clave: Educación Rural, Los Movimientos Sociales, Movimiento de los Pequeños Agricultores, La Agricultura Familiar. 


\section{Introdução}

A questão agrária brasileira nos remete ao início da colonização portuguesa, quando foram demarcadas e distribuídas as sesmarias para a nobreza de Bragança (Stédile, 1997, p. 9). Essa distribuição de terras negligenciava a existência de habitantes nativos na então colônia portuguesa. Ao longo de todo regime colonial, a sustentação econômica da principal colônia portuguesa foi fundamentada na grande propriedade, monocultura e trabalho escravizado (Alencastro, 2000, p. 353). Mesmo após a instauração da República em 1889, os grandes proprietários de terras continuaram dando as cartas políticas e econômicas no Brasil. Tanto na República, quanto no regime colonial, houve movimentos de resistências pela democratização do acesso à terra. Durante toda primeira metade do século XX no Brasil várias vozes lutaram abertamente em favor da reforma agrária, conquistando espaços na política e obtendo algumas vitórias (Stédile, 1997, p. 11). No entanto, com o Golpe Civil Militar em 1964, as questões fundiárias foram totalmente amordaçadas. Para (Stédile, 1997, p. 16):

Os vinte anos de regime militar no Brasil representaram um amordaçamento da questão agrária ... o modelo adotado pelos governos desse período foi muito claro; estimular o desenvolvimento do capitalismo na agricultura, baseandose na grande propriedade latifundiária e atrelando-se aos interesses do capital estrangeiro, vinculado com um processo de industrialização acelerada na cidade, também baseado nos investimentos de empresas multinacionais.

O revigoramento do capitalismo agrário no regime militar perdura até hoje. O Estado brasileiro, além de não promover uma ampla reforma agrária, não investe adequadamente na agricultura familiar. Percebe-se que a prioridade das políticas públicas é investir e fomentar a grande propriedade, valorizando o agronegócio. Os movimentos sociais do campo, em especial, o Movimento dos Pequenos Agricultores - MPA são fundamentais na consolidação das lutas e reivindicações junto ao poder público, valorizando a educação do campo, a agricultura familiar, orgânica, agroecológica e as questões agrárias, como um todo.

Nessa conjuntura, é importante conhecermos os desafios das políticas públicas em educação do campo e as tensões estabelecidas entre movimentos sociais camponeses e Estado. O embate entre estas duas categorias resultou em experiências históricas e na contribuição dos sujeitos de direitos, individuais e coletivos, do campo, direcionarem outras formas de lutas. Nos últimos anos foram identificadas muitas práticas educativas, 
em todas as regiões do país, originadas no interior das organizações e movimentos sociais do campo. Com o objetivo de garantir a educação básica nas comunidades rurais e a formação de quadros dirigentes, muitas dessas ações, ainda que isoladas, obtiveram resultados concretos, fortalecendo as escolas do campo, os agricultores familiares, seus movimentos sociais e organizações. Pressionado pelos sujeitos camponeses, coube ao estado reconhecer estas experiências e desenvolver políticas públicas específicas para o campo, de modo que as referidas práticas educativas foram ampliadas e reconhecidas pela sociedade. Neste cenário, o Programa Nacional de Educação na Reforma Agrária (PRONERA), o Programa de Apoio à Formação Superior em Licenciatura em Educação do Campo (PROCAMPO) e o Programa Nacional de Educação na Reforma Agrária (PRONACAMPO), foram fundamentais para promover melhorias na vida do coletivo rural, em especial, sua contribuição na formação de professores para o campo e a relevância de tais políticas públicas no século XXI. (Molina, 2003, Molina \& Jesus, 2010).

Importante ressaltar neste debate, a contribuição do Programa de Educação Tutorial - PET $^{\mathrm{i}}$ Educação do Campo e Movimentos Sociais no Estado do Rio de
Janeiro, vinculado à Universidade Federal Rural do Rio de Janeiro - UFRRJ, Campus Seropédica, desenvolve inúmeras ações socioambientais, agroecológicas, políticas e culturais referentes à História da Educação do Campo e sua estreita relação com os movimentos sociais, em especial, o Movimento dos Trabalhadores Rurais Sem Terra e a Comissão Pastoral da Terra. Nossa proposta interdisciplinar envolve estudantes das Licenciaturas da Universidade, prioritariamente, da Licenciatura em Educação do Campo LEC, oriundos de diversos movimentos sociais do campo e da cidade. Nosso PET, em articulação com a Licenciatura em Educação do Campo, aproxima a produção acadêmica dos anseios comunitários, por meio de debates, minicursos e eventos artístico-culturais com os sujeitos, individuais e coletivos, do campo, contemplando a formação continuada de educadores e educandos. Desenvolvemos atividades de ensino, pesquisa e extensão, refletindo sobre as desigualdades, contradições e possibilidades das escolas do campo, as demandas de educadores, educandos e demais atores articulados às questões do campo e da pedagogia da alternância.

O processo de institucionalização da educação do campo é uma realidade em diversas Universidades Federais Brasileira. 
Na UFRRJ, o PET Educação do Campo e Movimentos Sociais vem contribuindo no fortalecimento desse debate. Os fóruns, seminários e encontros que se aceleraram entre os anos de 1997 a 2016, a partir das demandas crescentes nas áreas de reforma agrária no Estado do Rio de Janeiro e de escolarização dos trabalhadores rurais na agricultura familiar, orgânica e agroecológica, também foram essenciais. Nessa conjuntura, defendemos, políticas públicas em educação do campo, voltadas para o desenvolvimento econômico dos assentamentos da reforma agrária, além da valorização intelectual e cultural dos trabalhadores rurais, seus filhos e movimentos sociais, materializada na democratização e acesso à escolarização de ensino médio e superior, além do respeito às diversidades culturais, étnicas $\mathrm{e}$ territoriais.

\section{Estratégias metodológicas do PET no trabalho com os pequenos agricultores}

Por mais que este artigo se detenha em analisar referências bibliográficas e documentais, faz-se necessário, apresentar ao leitor, que o PET Educação do Campo e Movimentos Sociais, se fundamenta numa metodologia formulada a partir das demandas advindas dos seminários, fóruns e encontros sobre educação do campo, juventude rural, movimentos sociais, agricultura familiar, agroecológica e orgânica presente nas atividades organizadas pela Universidade Federal Rural do Rio de Janeiro. Nesse sentido, este artigo é fruto dos trabalhos desenvolvidos pelo PET. Nesta investigação utilizamos a pesquisa qualitativa, considerando o universo das crenças, valores, atitudes, motivações e histórias dos sujeitos individuais e coletivos. Ela permitiu uma inserção social mais profunda na realidade, explorando a diversidade de materiais bibliográficos vinculados aos movimentos sociais do campo no Estado do Rio de Janeiro, em especial, o Movimento dos Pequenos Agricultores - MPA, além de legislações, decretos e portarias que tratam da educação do campo no Brasil, na sua estreita relação com as políticas públicas, formação docente, projeto político pedagógico, desenvolvimento socioeconômico, agricultura familiar, orgânica e agroecológica. Nas atividades de ensino e extensão conhecemos melhor os movimentos sociais estudados, tendo acesso a importantes documentos oficiais e interagindo com os grupos de pesquisa vinculados ao PET Educação do Campo e Movimentos Sociais no Estado do Rio de Janeiro, vinculado à Universidade Federal Rural do Rio de Janeiro - UFRRJ, Campus Seropédica. Nessa conjuntura, exploramos 
um universo de significações, conhecimentos, identidades, memórias, experiências, atitudes e diversidade de crenças. Com tal metodologia aprofundamos a compreensão da realidade, respeitando as experiências pessoais, sociais e comunitárias dos indivíduos, seus coletivos e vivências familiares, a partir dos documentos e materiais bibliográficos consultados.

Focalizamos as relações entre as histórias de vida das pessoas, no envolvimento com as lutas organizadas pelos movimentos sociais do campo, contribuindo para formação de novos sujeitos sociais, numa perspectiva popular e histórica. Acreditamos nessa dimensão educativa e no fazer pedagógico que tais sujeitos realizam através da organização coletiva e no fortalecimento de projetos políticos pedagógicos emancipadores. Reitero a realização de um amplo levantamento de materiais bibliográficos e leituras interpretativas dos documentos que norteiam a educação do campo nos movimentos sociais. Importante ressaltar que a observação e a participação indireta foi uma das técnicas utilizadas, em especial, por se tratar de pesquisas na área de ciências humanas e sociais. Embora seja uma técnica relativamente espontânea, a observação exige intensa participação dos sujeitos da pesquisa.
A metodologia utilizada no PET Educação do Campo e Movimentos Sociais está articulada às oficinas pedagógicas realizadas nos anos de 2015 e 2016, com as escolas do campo na Baixada Fluminense, Rio de Janeiro. Ela contribui para o reforço escolar, melhoria dos índices de escolarização nas escolas do campo e qualidade da educação pública na vida das populações camponesas, fortalecendo laços de interação com movimentos sociais, secretarias estaduais e municipais de educação. Em termos operacionais, dialogamos com a diversidade dos sujeitos, individuais e coletivos, do campo, desenvolvendo atividades de ensino, extensão e pesquisas em história da educação do campo, agricultura familiar e agroecológica, educação popular, pedagogia da alternância, movimentos sociais e formação do educador nas licenciaturas em educação do campo. Realizamos debates teórico-metodológicos sobre educação do campo e temas correlatos, revisão bibliográfica, trabalhos de campo, mapeamento de ações conjuntas, troca de experiências, rodas de conversas, participação em congressos, projetos de extensão universitária, minicursos, palestras e outras atividades de ensino que colaborem para formação dos sujeitos, por meio da atuação crítica e coletiva. As atividades desenvolvidas pelo 
PET Educação do Campo e Movimentos Sociais contribuíram para aprofundarmos a interface entre Movimento dos Pequenos Agricultores, agricultura familiar e educação do campo.

Essas estratégias metodológicas aproximam universidade e comunidade, aliadas ao compromisso de valorização das identidades, memórias e histórias de vida dos sujeitos, individuais e coletivos, do campo. Buscamos compreender a dinâmica da realidade local de atuação do MPA, suas questões políticas, socioambientais e de infraestrutura, considerando a indissociabilidade prática entre ensino, pesquisa e extensão. Entendemos que a metodologia adotada nesta pesquisa, contribuiu na divulgação das seguintes políticas públicas específicas de educação do campo: Programa Nacional de Educação na Reforma Agrária (PRONERA), integrado ao Ministério do Desenvolvimento Agrário; Programa de Apoio à Formação Superior em Licenciatura em Educação do Campo (PROCAMPO) e Programa Nacional de Educação do Campo (PRONACAMPO), ambos vinculados ao Ministério da Educação. Defendemos a estreita relação entre tais políticas públicas de educação do campo com o Movimento dos Pequenos Agricultores, a agricultura familiar, orgânica e agroecológica.

\section{O Movimento dos Pequenos Agricultores - MPA}

Hoje, muito mais organizado do que no início de sua estruturação, o MPA é, além de tudo, um movimento de caráter nacional e popular, constituído por grupos de famílias camponesas. Sua finalidade central é a produção de alimentos saudáveis para toda população brasileira. Dentro das disputas agrárias que perduram até hoje, encontramos o Movimento dos Pequenos Agricultores - MPA. Ele surge após a crise do movimento sindical rural com o objetivo principal de buscar soluções para melhoria da qualidade de vida dos pequenos agricultores e da agricultura familiar brasileira. Essa crise se agravou no extenso período de seca que atingiu o Estado do Rio Grande do Sul, no ano de 1996. Por conta das dificuldades vivenciadas pela seca e o caos sindical, os agricultores protestavam, exigindo mais apoio do governo (Picolotto, 2008, p. 6). A partir dessas reivindicações, os agricultores familiares constroem as principais características do MPA. Segundo (Görgen, 2012, p. 494): “O MPA é um movimento camponês, de caráter nacional e popular, de massa, autônomos, de luta permanente, na sua base estão grupos de família organizados". Esse movimento tem como objetivo produzir comida saudável para o consumo dos brasileiros do campo e da 
cidade, além de resgatar a identidade e cultura camponesa, respeitando as diversidades regionais (Candoná, 2004, p. 204).

A crise que desencadeou o surgimento do MPA foi originada pela seca que afetou as plantações entre os anos de 1995 e 1996 no Rio Grande do Sul. Essa estiagem aliada à grave situação existente entre os pequenos agricultores que não contavam com políticas de subsídios propiciou um racha entre os sindicalistas da Federação dos Trabalhadores na Agricultura do Rio Grande do Sul (Fetag-RS) que optavam pela via do acordo, sem pressão, e os que decidiram acampar às margens das rodovias reivindicando melhorias na situação do pequeno agricultor. Segundo (Görgen, 2012, p. 494):

\begin{abstract}
A articulação da mobilização dos atingidos pela seca levou de roldão muitos dirigentes sindicais que estavam "em cima do muro". Houve uma ruptura política entre os que optaram pela via do acordo, sem pressão, e os que foram acampar às margens das rodovias. Aquilo foi um divisor de águas. Na verdade, a mobilização da seca provocou uma avaliação profunda sobre o modo da atual organização sindical e sobre o método de organização das lutas políticas.
\end{abstract}

Cinco foram os acampamentos da seca que se organizaram nos meses de janeiro e fevereiro de 1996 no Rio Grande do Sul, reunindo mais de 25 mil pequenos agricultores. Ali germinou a semente do MPA, que nasceu da pressão da base organizada e da luta dos agricultores para resistir na roça. Nasceu também para lutar pela mudança da política agrícola, por crédito subsidiado, seguro agrícola e construção de um novo modelo para agricultura brasileira. (Görgen, 2012, p. 494-495).

O MPA está organizado em 17 estados e se articula com diversos movimentos sociais e organizações que compõem a Via Campesina Brasil: Movimento dos Trabalhadores Rurais Sem Terra - MST, Movimento de Mulheres Camponesas - MMC, Pastoral da Juventude Rural - PJR, Federação dos Estudantes de Agronomia do Brasil FEAB, Articulação dos Povos e Organizações Indígenas, pescadores artesanais, pastorais sociais - APOINMI, Rede de Educação Cidadã, Universidades RECID, Articulação popular pela revitalização do Rio São Francisco e outros grupos populares. (MPA, 2016). Uma das principais ações do MPA é criar um campesinato independente, que enfrente os males oriundos do capital. Nesse sentido, o MPA criou um programa que une, de forma equilibrada, geração de energia, produção de alimentos e preservação do meio ambiente. Esse projeto está inserido 
no interior do Plano Camponês, chamado de alimento / meio ambiente / energia ALIMERGIA. Seu principal objetivo é contribuir para que o pequeno agricultor familiar alcance, simultaneamente, a autossuficiência alimentar e energética. (Camacho, 2013, p. 77).

\section{Limites e possibilidades da agricultura familiar}

Importante registrar que durante a 66 ${ }^{\mathrm{a}}$ Sessão da Assembleia Geral da ONU foi declarado que 2014 seria o Ano Internacional da Agricultura Familiar. (ONU, 2014). Isso mostra o quanto é necessário a luta do Movimento dos Pequenos Agricultores - MPA, em busca de apoio para a agricultura familiar. O estabelecimento do Ano da Agricultura Familiar representa um momento importante de reflexão sobre os modelos de desenvolvimento adequados à promoção da segurança alimentar. Além disso, tem como objetivo recolocar a agricultura familiar no centro das políticas públicas, sociais, econômicas, agrícolas e ambientais dos países membros ${ }^{\mathrm{ii}}$.

A grandeza da temática agricultura familiar é visibilizada quando nos deparamos com as estimativas da Organização das Nações Unidas para Alimentação e Agricultura - FAO: 2,5 bilhões de pessoas no mundo dependem diretamente do setor de agricultura e alimentos e 1,5 bilhão vivem e trabalham em cultivos familiares. Segundo a FAO, esses agricultores familiares estão mais concentrados na Ásia e África. As pequenas propriedades rurais nos países em desenvolvimento podem chegar a 500 milhões. A criação do Ano Internacional da Agricultura Familiar fortalece as lutas travadas pelo MPA e mostra que os agricultores familiares têm um papel fundamental na manutenção da segurança alimentar, no crescimento econômico, na redução da pobreza, diminuição das desigualdades e na gestão sustentável dos recursos naturais em todo o mundo.

Segundo o último censo agropecuário realizado em 2006 pelo Instituto Brasileiro de Geografia e Estatística - IBGE, a agricultura familiar é responsável pela produção dos alimentos que vão para mesa dos brasileiros, sendo, aproximadamente, $88 \%$ da produção de mandioca, $68 \%$ da produção de feijão, $47 \%$ do milho, $38 \%$ do café, $35 \%$ do arroz e $21 \%$ do trigo. (França, Grossi \& Marques, 2009, p. 27). Na pecuária, 58\% do leite, $59 \%$ do plantel de suínos, 50\% das aves e $30 \%$ dos bovinos. (IBGE, 2006). Analisando os dados do censo agropecuário de 2006, compreendemos que a agricultura familiar é responsável por $38 \%$ do valor bruto da produção 
agropecuária, mesmo ocupando pouco mais de $24 \%$ da área total dos estabelecimentos rurais. A agricultura familiar também exerce uma importante fonte de ocupação da força de trabalho. Ela abrange $74 \%$ dos trabalhadores rurais. A agricultura familiar camponesa gera um valor bruto da produção por área total de $\mathrm{R} \$ 677,00$ reais por hectare, $89 \%$ superior ao gerado pela agricultura patronal, de $\mathrm{R} \$$ 358,00 por hectare. A agricultura familiar no Brasil exerce um importante papel como principal fonte de abastecimento do mercado interno. No entanto, os agricultores familiares ainda carecem de políticas públicas eficazes. Os programas de governo, em sua grande maioria, ainda privilegiam os latifundiários, com produção voltada para o mercado externo.

Esses dados do IBGE nos mostram que o título de atrasado, atribuído ao campesinato não tem validade e reflete a encarnação de uma força ideológica para a desmobilização do pensamento social sobre os pequenos agricultores. Movimentos sociais como o MPA apontam para a necessidade de um novo modelo agrícola que tenha como prioridade a soberania alimentar pautada na agricultura familiar, pois como vimos, mesmo sendo submetida às condições de opressão e pouca terra, ausência de incentivo, crédito reduzido, "consegue-se produzir em quantidade suficiente para alimentar a população, ao mesmo tempo denuncia-se a finalidade pautada no lucro da produção capitalista do agronegócio, que através de produtividade não resolverá o problema da fome e pobreza no campo". (Santos, 2016. p. 17).

Um exemplo dessa desigualdade de investimentos por parte do governo é o Plano Safra 2015/2016. Foram destinados $\mathrm{R} \$ 187,7$ bilhões à agricultura empresarial e apenas R\$ 28,9 bilhões para os produtores familiares iii $^{\text {. Esse quadro }}$ desigual justifica a luta do Movimento dos Pequenos Agricultores que, para diminuir tal desigualdade, criou o Plano Camponês, elaborado a partir de muitos debates e estudos sobre a realidade do campesinato brasileiro. (MPA, 2016). Esse Plano, além de afirmar o campesinato como sujeito político, expõem um conjunto de ações econômicas, políticas e culturais que traduzem, concretamente, os objetivos do MPA, dentre eles: produção de comida saudável e qualidade de vida no campo. $\mathrm{O}$ Plano Camponês se contrapõem diretamente ao latifúndio, às multinacionais e seu capital financeiro, idealizados pelo agronegócio. (Leite \& Medeiros, 2012, p. 83).

\section{Os fundamentos básicos do plano camponês}


Em resposta à inexistência de políticas públicas de maior alcance e em função da necessidade de enfrentamento ao agronegócio exportador e opressor do pequeno agricultor, o MPA vem trabalhando na identificação das principais características do campesinato brasileiro, formulando inúmeras bandeiras de lutas. A intenção é consolidar projetos estratégicos para o campesinato em âmbito nacional. Tal projeto é sintetizado pelo MPA sob a configuração do plano camponês. Seu objetivo é afirmar o campesinato como sujeito político e, para tanto, traz consigo um conjunto de ações econômicas, políticas e culturais que traduzem, concretamente, os objetivos do movimento. (Silva, 2014, p. 32).

O plano camponês consiste na interligação dos sistemas camponeses de produção e as agroindústrias. Tais sistemas vão desde a produção de sementes, oleaginosas, leite, alimentos em geral, adubação verde e orgânica, até os sistemas agroflorestais, além do processamento e comercialização dos derivados do leite, mel, café, óleos, erva mate, cana, entre outros. A intenção do plano camponês é oferecer condições para uma produção saudável e limpa, criando "meios de comercialização direta com o consumidor, garantindo preço justo para quem vende e compra”. (MPA, 2016).
O plano camponês defende a valorização da educação básica, o ensino superior e a educação popular, considerando o cotidiano de educadores e educandos, a interação com o campo, os camponeses/as e seus movimentos sociais. Sugere que as escolas do campo tratem os conteúdos curriculares de acordo com o ambiente local, as histórias de vida, memórias e identidades das comunidades. A universidade deve trazer para o debate a realidade camponesa. Ela tem a obrigação de estar "acessível aos trabalhadores do campo, e pensar um conhecimento que esteja voltado para a agricultura camponesa, e não para o agronegócio, como acontece atualmente". (MPA, 2016). Essa articulação pode contribuir com a produção crítica e emancipadora do conhecimento, fortalecendo os debates acerca da educação do campo nas reuniões, seminários, congressos e oficinas. (Silva, 2009, p. 61).

Outra questão tratada no plano camponês é a qualidade de vida das famílias que residem no campo. Para viver com qualidade é extremamente necessário o acesso à moradia, esporte, cultura, lazer, escolas do campo e saúde popular. A residência do camponês não pode ser apenas um abrigo. Nesse espaço, os agricultores familiares cultivam seu pomar, apreciam as flores do jardim, preservam o 
meio ambiente, vivem em família $\mathrm{e}$ comunidade. Ter uma boa moradia é de grande importância para os sujeitos do campo. Tal plano enfatiza, inclusive, a importância da destinação de espaços para práticas esportivas, tais como: campos de futebol, quadras de vôlei, entre outros. (Silva, 2014, p. 32).

O esporte é uma importante atividade de interação, mas que não substitui as festas, bailes, torneios e encontros das famílias camponesas. Todas essas coisas, aliadas a uma agenda cultural com teatro, música, atividades de partilha, mutirões, vão garantir a qualidade de vida camponesa pela qual o MPA tanto luta. (MPA, 2016).

O plano camponês fortalece $\mathrm{o}$ convívio em comunidade e deixa clara a necessidade de valorização do trabalho coletivo, construindo laços unificados com os sujeitos, individuais e coletivos, do campo. Nesse sentido, é importante garantir estruturas comunitárias mínimas, com espaços coletivos que podem ser utilizados pelas famílias da comunidade, incentivando trabalhos coletivos com mutirões. Essas são ações que envolvem cooperação, solidariedade e ajudam no fortalecimento da comunidade. (Silva \& Schneider, 2014, p. 55). Reiteramos que as escolas do campo podem se tornar espaços importantíssimos para vivência comunitária.
Observamos que a proposta do Plano Camponês para a educação contempla desde a pré-escola até a educação universitária, garantindo escolas nas comunidades e conteúdos que se fundamentem na realidade de cada região. O Plano Camponês entende que as escolas do campo não terminam em si mesmas, elas se constituem em espaços de articulação e sistematização do conhecimento da comunidade, capaz de problematizar e criar instrumentos que resolvam suas necessidades. (COORDENAÇÃO NACIONAL, 2014, p. 94).

O MPA, por meio do plano camponês, defende a soberania alimentar, energética, genética e hídrica. A soberania alimentar está vinculada à cultura e à condição de vida dos sujeitos camponeses. Para se alcançar tal soberania, é preciso produzir uma grande variedade de alimentos. No entanto, não basta apenas produzir de qualquer maneira. A produção deve ser limpa, sem veneno e preocupada com o equilíbrio ambiental. (MPA, 2016). O plano defende a necessidade de diversificação da matriz energética. Existe uma grande variedade de fontes energéticas pouco exploradas, causando pouquíssimos danos ao meio ambiente: ventos, biomassa, sol e biogás. (Silva, 2014, p. 32). A soberania genética é uma 
temática extremamente pertinente para $o$ pequeno produtor rural. O plano camponês enfatiza que os pequenos agricultores não podem ficar reféns das sementes transgênicas, controladas por laboratórios de grande porte. Nessa conjuntura, metas são traçadas para consolidar técnicas de recuperação, armazenagem e melhoramento das sementes dos camponeses. (Silva \& Schneider, 2014, p. 40). Valorização da semente crioula, patrimônio da humanidade.

A água é outra questão de extrema importância para quem vive da agricultura familiar, orgânica e agroecológica. Segundo o plano camponês, a garantia da soberania hídrica pelo pequeno produtor está relacionada com a recuperação das nascentes, o desenvolvimento de pequenos sistemas de irrigação, execução de técnicas de coleta e armazenagem da água. (Silva, 2009, p. 57). O plano camponês foi elaborado como resposta às elites e aos programas governamentais que submetem o camponês a condições degradantes. Para o MPA, o plano é referência na construção de uma nova sociedade. Ele representa um projeto político que, ao mesmo tempo, denuncia os efeitos do agronegócio na agricultura e investe numa sólida proposta política, construída coletivamente. (Silva, 2014, p. 33).

\section{Políticas públicas em educação do campo}

Neste campo de análise, privilegiamos as relações entre $\mathrm{O}$ Movimento dos Pequenos Agricultores, educação do campo e agricultura familiar, considerando as seguintes políticas públicas $^{\text {iv }}$ Programa Nacional de Educação na Reforma Agrária PRONERA; Programa de Apoio à Formação Superior em Licenciatura em Educação do Campo - PROCAMPO e o Programa Nacional de Educação do Campo - PRONACAMPO. Focalizamos as relações entre as histórias de vida de educadores(as) e educandos(as), no envolvimento com as lutas organizadas pelos movimentos sociais do campo, contribuindo para formação de novos sujeitos sociais, numa perspectiva popular e histórica. Acreditamos nessa dimensão educativa e no fazer pedagógico que educadores(as) das escolas do campo realizam através da organização coletiva e no fortalecimento de projetos políticos pedagógicos emancipadores. (Freire, 1975, 1997).

Neste tópico, muito rapidamente, mostramos a relevância dos princípios desenvolvidos pelos movimentos sociais no que toca à luta por uma educação do campo. Suas bandeiras, projetos, perspectivas e utopias. A formação política 
dos agricultores familiares e a valorização da consciência social são alguns dos desafios. A produção de tal conhecimento pode ressignificar memórias, identidades e histórias vividas pelos sujeitos camponeses que se articulam para superar a opressão e as diversas cercas do analfabetismo e da fome que atingem milhares de homens e mulheres no campo.

Acreditamos que a formação política contextualizada pode contribuir na reconstrução do passado, escavando memórias e acontecimentos, valorização das experiências coletivas, gestação de embriões de democratização, socialização de poder, superação dos desafios, afirmação de identidades e seres humanos preocupados com o fortalecimento de ambientes emancipadores. Existe hoje, nos espaços formais e informais da produção do conhecimento, uma urgente necessidade de intervenção, propondo reflexões que tenham por meta problematizar as dificuldades apresentadas quanto às questões teórico-metodológicas da educação do campo, na perspectiva crítica, dialógica e histórica do saber. (AntunesRocha, 2010). Tais aspectos enaltecem os processos identitários ligados à visão de hegemonia no campo agrário, reconfigurada pelos atores políticos. (Molina \& Jesus, 2010).
A expressão educação do campo identifica uma reflexão pedagógica que germina das inúmeras práticas educativas desenvolvidas pelos sujeitos que vivem no campo. Consiste numa reflexão que considera o campo como espaço onde se produz pedagogias. Trata-se, também, de um projeto que reafirma a finalidade mais expressiva das práticas educativas desenvolvidas no campo, contribuindo com o desenvolvimento mais pleno do ser humano e sua inserção consciente no contexto social do qual faz parte. (Caldart, 2002). A realidade de intensa desumanização que, historicamente, caracteriza a vida da população camponesa, gerou este movimento em favor da educação básica do campo. Uma realidade que mesmo marcada por opressões e injustiças, continua reivindicando alterações sociais, profundas e imediatas, no campo brasileiro.

O processo de exclusão social, político e econômico acompanha a história do Brasil desde o seu surgimento, como se fosse condição inerente desta sociedade, firmada sob o caráter elitista. Contudo, a luta dos movimentos sociais pelo direito à educação produziu inúmeras conquistas em favor do desenvolvimento do campo brasileiro. Segundo (Caldart, 2002), o movimento por uma educação do campo se vincula a outras lutas, em favor de 
transformações que garantam melhores condições de vida para a população camponesa. Esta conexão se justifica pela impossibilidade de educar o povo sem modificar as condições que o desumaniza.

Dentre as conquistas adquiridas por este movimento, é notório ressaltar, neste cenário, as seguintes políticas públicas: Programa Nacional de Educação na Reforma Agrária (PRONERA), Programa de Apoio à Formação Superior em Licenciatura em Educação do Campo (PROCAMPO) e o Programa Nacional de Educação do Campo (PRONACAMPO). Estas políticas representam a capacidade de articulação dos movimentos sociais e apontam a crescente necessidade de garantir projetos populares para o campo, cuja organização tenha como referência a cultura e o trabalho dos grupos sociais.

O debate acerca da educação do campo deve, portanto, entender a complexidade da dimensão do campo brasileiro, constituído por paisagens, lutas, organicidade, histórias, memórias, identidades e modos de vida. Neste contexto, as políticas públicas permitem reafirmar este espaço e legitimar as lutas que dali advém. São, portanto, necessárias para a consolidação de um projeto popular para todo o país. As conquistas oriundas do PRONERA, PROCAMPO e PRONACAMPO, enquanto políticas públicas, somente serão compreendidas se interpretadas às tensões estabelecidas nas relações entre os movimentos sociais camponeses e o Estado. $\mathrm{O}$ embate entre estas duas categorias resultou em experiências históricas para as organizações populares direcionarem outras formas de lutas e posicionamentos, como sujeitos de direitos.

\section{Considerações finais}

Entendemos que o artigo em questão, fruto das pesquisas desenvolvidas pelo Programa de Educação Tutorial - PET Educação do Campo e Movimentos Sociais na Universidade Federal Rural do Rio de Janeiro - UFRRJ, deu conta dos seus principais objetivos, em especial, o protagonismo do plano camponês desenvolvido pelo Movimento dos Pequenos Agricultores - MPA e as relações estabelecidas com a agricultura familiar e educação do campo. Vale destacar que mesmo com tantos avanços nas legislações voltadas para educação do campo, a realidade das escolas que atendem às populações camponesas continua ainda muito precária. As políticas e ações relatadas estão em diferentes patamares de desenvolvimento. Sendo assim, é importante defender a construção de uma política nacional de educação do campo, a partir do diálogo com as diversas esferas 
da gestão do Estado, com os movimentos e organizações sociais do campo brasileiro, considerando alguns eixos orientadores: agricultura familiar, orgânica e agroecológica, diversidade étnico-cultural como valor, reconhecimento do direito à diferença, promoção da cidadania e construção de uma base epistemológica que supere a dicotomia campo-cidade. Essas ações poderiam implicar no fortalecimento da educação do campo, e nela, os movimentos sociais, a segurança alimentar e o desenvolvimento sustentável.

Consideramos que a luta por uma educação do campo deve ir além do que prescreve a Constituição de 1988, a LDB 9394/96, as Diretrizes Operacionais, o PROCAMPO, o Decreto Presidencial $n^{\circ}$ 7.352, que dispõe sobre a política de educação do campo e o Programa Nacional de Educação na Reforma Agrária PRONERA, no final do governo Lula e o PRONACAMPO. Deve se constituir fundamentalmente pelos atores, que nela estão envolvidos, através de suas práticas educativas cotidianas, suas experiências e reais necessidades. Faz-se necessário materializar políticas e ações de educação do campo que sejam realmente concretizadas e perspicazes nas inúmeras localidades desse território nacional.

Esse debate deve, com urgência, enfrentar o individualismo, o voluntarismo, as atitudes que geram apenas um amontoado de palavras "boas e bonitas", discursos e oratórias distantes das diversas realidades campesinas desse nosso Brasil. Importante reafirmar que as políticas públicas específicas reivindicadas pelo movimento da educação do campo têm sua gênese e sustentação no protagonismo das organizações e movimentos sociais camponeses. À medida que se eleva a consciência dos sujeitos, individuais e coletivos, sobre seus direitos, novas políticas públicas são exigidas e, assim, se justifica o fato de serem os movimentos sociais os mais engajados nessa luta, uma vez que "são esses movimentos os grandes educadores coletivos da nova consciência política dos direitos". (Arroyo, Molina \& Jesus, 2004, p. 60). Nesta perspectiva histórica, cabe novamente destacar, que o PET Educação do Campo e Movimentos Sociais contribui, significativamente, para formação crítica de educadores e educandos na UFRRJ e nas escolas do campo da Baixada Fluminense/RJ, consolidando posturas, socialmente compromissadas, diante de práticas científico-acadêmicas.

Compreendemos que no Brasil a questão agrária, em sua grande maioria, foi negligenciada e o foco principal dos governantes é a valorização da grande propriedade e da monocultura. Nessa 
conjuntura, o Movimento dos Pequenos Agricultores - MPA desenvolve lutas históricas por melhores condições de vida, reivindicando diversas políticas públicas voltadas para os agricultores familiares. Organizado em várias frentes, o MPA se utiliza do plano camponês para consolidar algumas estratégias essenciais de enfrentamento na disputa política e social contra o agronegócio. Aqui defendemos a agricultura camponesa, comprovadamente mais eficiente que a agricultura patronal. Mesmo possuindo menores porções de terras e financiamentos escassos, produzem e empregam mais que o agronegócio. Entendemos que é nossa responsabilidade enfrentar o descaso do poder público com a agricultura familiar, mesmo sendo ela uma das principais ferramentas de subsistência e oferta de alimentos saudáveis para a população mundial.

\section{Referências}

Alencastro, L. F. (2000). O Trato dos Viventes: Formação do Brasil no atlântico Sul - Séculos XVI e XVII. São Paulo: Companhia das Letras.

Antunes-Rocha, M. I. (2010). Formação de educadores e educadoras da Reforma Agrária no contexto do PRONERA: uma leitura a partir das práticas. In Santos, C. A., Molina, M. C., \& Jesus, S. M. S. A. (Orgs.). Memória e história do Pronera: contribuições para a educação do campo no Brasil. (p. 121-137). Brasília: Ministério do desenvolvimento Agrário.
Arroyo, M. G., Molina, M. C., \& Jesus, S. M. S. A. (2004). (Orgs). Contribuições para a construção de um projeto de educação do Campo - Brasília, DF: Articulação Nacional Por uma Educação Básica do Campo. Coleção Por uma Educação Básica do Campo, (5).

Blog do Itamaraty. (2014). 2014 ano internacional da agricultura familiar. Disponível em :< http://diplomaciapublica.itamaraty.gov.br/2 5-combate-a-fome/46-2014-anointernacional-da-agricultura-familiar> Acessado em: 05 Jul. 2016.

Brasil. (2010). Decreto $n^{o} 7.352$, de 4 de novembro de 2010. Dispõe sobre a política de educação do campo e o Programa Nacional de Educação na Reforma Agrária -PRONERA. Diário Oficial da União, Brasília, Sessão1, 5 nov. 2010. Disponível em:

http://www.planalto.gov.br/ccivil_03/_ato2 007-010/2010/decreto/d7352.htm. Acesso em 26 de junho de 2015.

Caldart, R. S. (2002). Por Uma Educação do Campo: traços de uma identidade em construção. In Kolling, E. J., Cerioli, P. R., \& Caldart, R. S. (Orgs.). Educação do Campo: identidade e políticas públicas. (p. 25-36.). Brasília. Coleção Por Uma Educação do Campo.

Camacho, R. S. (2013). Soberania Alimentar e Energética: A proposição camponesa para uma nova relação da sociedade/natureza. IX Fórum Ambiental da Alta Paulista, 9(10), 76-91.

Candoná, C. V. (2004) Movimento dos pequenos agricultores - MPA: $\mathrm{O}$ novo nasce das estradas. (Tese de Doutorado). Universidade Regional do Noroeste do Rio Grande do Sul. 
Coordenação Nacional. (2014). Afirmando o conceito de educação camponesa no MPA. Caderno de Estudos, 1(1), 92-97.

Delgado, G. C. (2010). A questão agrária e o agronegócio no Brasil. In Carter, M. (Org.). Combatendo a desigualdade social: o MST e a reforma agrária no Brasil. (p. 81-112), São Paulo: Unesp.

França, C. G., Grossi, M. E., \& Marques, V. P. M. (2009). O censo agropecuário 2006 e a agricultura familiar no Brasil. Brasília: MDA.

Freire, P. (1997). Pedagogia da Autonomia: Saberes necessários à prática educativa. SP: Paz e Terra.

(1975). Pedagogia do Oprimido. RJ: Paz e Terra.

Görgen, F. S. A. (2012). Movimento dos Pequenos Agricultores (MPA). In Caldart et al. (Orgs.). Dicionário da Educação do Campo. (p. 494-497.). Rio de Janeiro: Expressão Popular.

IBGE. (2006). Censo agropecuário 2006. Disponível em: < http://biblioteca.ibge.gov.br/index.php/bibl ioteca-catalogo? view $=$ detalhes \&id $=750>$

Acesso em: 20 de Jun. 2016.

Leite, S. P., \& Medeiros, L. S. (2012) Agronegócio. In Caldart, R. et al. (Orgs.). Dicionário da Educação do Campo. (p. 81-87). Rio de Janeiro: Expressão Popular.

Ministério da Agricultura. Plano Safra 2015/2016. Disponível em: <http://www.agricultura.gov.br/arq_editor/ PAP\%20folder\%20web\%20v1.pdf $>$

Acesso em: 4 Jul. 2016.

Molina, M. C. (2003). A contribuição do PRONERA na construção de políticas públicas de educação do campo $e$ desenvolvimento sustentável. (Tese de Doutorado). Universidade de Brasília.

Molina, M. C., \& Jesus, S. M. S. A. (2010). Contribuições do PRONERA à Educação do Campo no Brasil: Reflexões a partir da tríade: Campo - Política Pública Educação. In Santos, C. A., Molina, M. C., \& Jesus, S. M. S. A. (Orgs.). Memória e história do Pronera: contribuições para a educação do campo no Brasil. (p. 29-63). Brasília: Ministério do desenvolvimento Agrário.

Movimento dos Pequenos Agricultores Brasil. (2012). Desenvolvimento rural brasileiro: cenário atual e desafios. Disponível em:< http://itarget.com.br/newclients/sober.org.b r/congresso2012/extra/pdf/Raul.pdf >

Acesso em: 4 Jul. 2016.

Movimento dos Pequenos Agricultores Brasil. MPA: uma alternativa de organização do campesinato brasileiro. Disponível em: $<$ http://www.mpabrasil.org.br/mpa-umaalternativa-de-organizacao-docampesinato-brasileiro\#regiao-menuprincipal> Acesso em: 19 jun. 2016.

Movimento dos Pequenos Agricultores Alagoas. Luta camponesa soberania alimentar e popular. Disponível em: <http://mpaalagoas.blogspot.com.br/search ?q=Pastorais+sociais, + Recid $>$ Acesso em: 19 Jun. 2016.

Movimento dos pequenos Agricultores Espírito Santo. Plano Camponês. Disponível em: < https://mpabrasiles.wordpress.com/planocampones/> Acesso em: 4 Jul. 2016.

Organização das Nações Unidas para Alimentação e Agricultura. (2014). Ano internacional da agricultura familiar 2014. Disponível 
http://www.fao.org/family-farming2014/pt/> Acessado em: 05 Jul. 2016.

Picolotto, E. L. (2008). Quando novos atores entram em cena o que muda? A construção de representação política dos agricultores de base familiar no Sul do Brasil. Espaço Acadêmico. Rio de Janeiro, (91).

Santos, R. M. (2016). A formação do Movimento dos Pequenos Agricultores MPA: por soberania alimentar, contra a mercadorização do campo no Brasil. Revista Nera, 19(31), 10-31.

Secretaria da Agricultura, Pecuária, Irrigação, Pesca e Aquicultura. Plano Safra 2015/2016. Disponível em: < http://www.seagri.ba.gov.br/sites/default/fi les/plano_safra_mda_2015_2016.pdf>

Acesso em: 4 Jul. 2016.

Silva, V. I. (2009). Caminhos $d a$ afirmação camponesa: elementos para um plano camponês. Tupanciretã: Rio Grande do Sul.

Silva, V. I. (2014). Elementos básicos para o debate sobre o campesinato rumo à construção de um plano camponês. Caderno de Estudos, 1(1), 31-35.

Silva, V. I., \& Schneider, G. A. (2014). Soberania Genética. Caderno de Estudos. 1(2), 40-42.

Stédile, J. P. (1997). A questão agrária no Brasil. São Paulo: Atual.

\footnotetext{
${ }^{\text {i }}$ Programa de Educação Tutorial - PET, vinculado ao Ministério da Educação - MEC / Secretaria de Educação Superior - SESu / Diretoria de Políticas e Programas de Graduação da Educação Superior. A Universidade Federal Rural do Rio de Janeiro UFRRJ possui um total de 14 Grupos PET em atividades.
}
ii Blog do Itamaraty. 2014 ano internacional da agricultura familiar. Disponível em: < http://diplomaciapublica.itamaraty.gov.br/25- combate-a-fome/46-2014-ano-internacional-da- agricultura-familiar> Acessado em: 05 Jul. 2016.

iii Ministério da Agricultura. Plano Safra 2015/2016. Disponível em: <http://www.agricultura.gov.br/arq_editor/PAP\%20 folder\%20web\%20v1.pdf > Acesso em: 4 Jul. 2016.

iv Refere-se a um conjunto de ações, atividades e programas desenvolvidos pelo Estado diretamente ou indiretamente, através da participação de entes públicos e privados, cujo propósito é garantir para determinado seguimento econômico, social, étnico e cultural ou de forma difusa o direito de cidadania. São direitos estabelecidos constitucionalmente que se afirmam por meio do reconhecimento dos poderes públicos e/ou por parte da sociedade enquanto novos direitos, sejam das pessoas, comunidades, coisas e dos bens materiais ou imateriais.

Recebido em: 03/10/2016

Aprovado em: 01/11/2016

Publicado em: 19/04/2017

Como citar este artigo / How to cite this article / Como citar este artículo:

APA:

Santos, R. B., \& Richard, D. (2017). O Movimento dos Pequenos Agricultores na interface entre agricultura familiar e educação do campo. Rev. Bras. Educ. Camp., 2(1), 86-105.

ABNT:

SANTOS, R. B.; RICHARD, D. O Movimento dos Pequenos Agricultores na interface entre agricultura familiar e educação do campo. Rev. Bras. Educ. Camp., Tocantinópolis, v. 2, n. 1, p. 86-105, 2017. 